\title{
Parameters Retrieval Principle and Algorithm form Polarimetric Microwave Radiometer
}

\author{
Rui Wang*, Shunwen Shi, Wei Yan, Ding Han,Huifa Liu \\ College of Meteorology and Oceanography \\ PLA University of Science and Technology \\ Nanjing,China \\ *wangruissw@126.com
}

\begin{abstract}
Polarimetric microwave radiometer is used to measuring target polarization information, whichopen up a new area for passive microwave remote sensing. In order to understand and use this new technology, further improve the capacity ofusingsatellite data toretrieve the parametersof sea surface and atmospheric physics, this article describes the construction of polarimetric microwave radiative transfer model,principle and algorithmsofatmospheric physical parameters inversion, as well as the sea surface wind vector. Studies have shown that polarimetric microwave radiometer could be widely used inthe retrievals of many parameters such as sea surface wind vector, sea surface temperature, water vapor content and cloud liquid water content, especially the polarimetric information is useful to remove the wind direction ambiguity.
\end{abstract}

Keywords-Polarimetric microwave radiometer;radiative transfer model;sea surface wind vector

\section{INTRODUCTION}

Polarimetric microwave radiometer developed as a new microwave remote sensing technology in the late 1990s. NRL (Naval Research Laboratory for the US Navy), IPO (Integrated Program Office / NOPESS), NASA (National Aeronautics and Space Administration) and other institutions promoted the first polarimetric microwave radiometer WindSat on the experimental satellites Coriolis which launch in 2003. WindSat is used to verify the reliability of the polarimetric microwave radiation sensor, construct wind speed and wind direction retrieval algorithm, provide the basis for the future business run of polarimetric microwave radiometer ${ }^{[1]}$.

To be carried out polarimetric microwave radiometer applications, which must be based on in-depth understanding of polarimetric microwave transmission theory, polarimetric microwave radiometer parameters inversion principle and its algorithm. This paper introduce polarimetric microwave radiative transfer model and parameter inversion problem systematically.

\section{POLARIMETRIC MICROWAVE RADIATIVE TRANSFER MODEL}

In order to adapt to the mission requirements of sea surface wind observations form WindSat, NRL constructed radiative transfer forward model for WindSat ${ }^{[2]}$, which is used to simulation brightness temperature of WindSat channels. The basic assumption is: plane-parallel atmosphere, no rain (no considering atmospheric scattering).Inputs of the model are observation frequency, incidence angle, sea surface temperature, ocean salinity, wind speed and direction at $10 \mathrm{~m}$ height, atmospheric water vapor content and cloud liquid water content.Outputs of the model are Stokes brightness temperature from radiometer.

Through polarized radiative transfer theory, brightness temperatures received by spaceborne polarimetric microwave radiometer can be expressed as:

$$
\left\{\begin{array}{l}
\mathrm{T}_{\mathrm{v}, \mathrm{h}}=\mathrm{T}_{\mathrm{up}}+\tau\left[\mathrm{e}_{\mathrm{v}, \mathrm{h}} \mathrm{T}_{\mathrm{s}}+\mathrm{r}_{\mathrm{v}, \mathrm{h}}\left(\Omega \mathrm{T}_{\text {down }}+\tau \mathrm{T}_{\mathrm{c}}\right)\right] \\
\mathrm{T}_{3,4}=\tau \mathrm{e}_{3,4}\left[\mathrm{~T}_{\mathrm{s}}-\left(\Omega \mathrm{T}_{\text {down }}+\tau \mathrm{T}_{\mathrm{c}}\right)\right]
\end{array}\right.
$$

Which $\mathrm{T}_{\mathrm{p}}(\mathrm{p}=\mathrm{v}, \mathrm{h}, 3,4)$ brightness temperature form a frequency on the satellite, subscript $p$ is channel polarization, $\mathrm{T}_{\text {up }}, \mathrm{T}_{\text {down }}$ is upward and downward atmospheric radiation brightness temperaturerespectively, $\tau$ is atmospheric transmittance, $e_{p}, r_{p}$ are sea surface emissivity and reflectivity, $\mathrm{T}_{\mathrm{s}}$ is sea surface temperature, $\Omega$ is correction factor for downward atmospheric radiation brightness temperature, $\mathrm{T}_{\mathrm{c}}$ is cosmic background temperature (about $2.7 \mathrm{~K}$ ). This model mainly consists of two parts that the atmosphere and the sea, with a single-layer atmospheric model and parametric algorithms, joined the sea scattering angle correction $\Omega$ and sea surface emissivity empirical correction, all of that is to resolve thecomputational problems with parameters $\tau, \mathrm{T}_{\mathrm{up}}, \mathrm{T}_{\mathrm{down}}, \mathrm{e}_{\mathrm{p}}, \mathrm{r}_{\mathrm{p}}$.

Within $1 \sim 37 \mathrm{GHz}$, even if cloudy or moderate intensity of precipitation, the atmosphere is quite transparent.For mainly absorbent component are $\mathrm{O}_{2}$ and $\mathrm{H}_{2} \mathrm{O}$, the atmospheric transmittance $\tau$ in vertical direction could be calculated with total oxygen absorption coefficient $A_{O}$, moisture absorption coefficient $A_{V}$ and cloud liquid water absorption coefficient $A_{L}$ from observation angle $\theta$ : 


$$
\tau=\exp \left[-\sec \theta\left(A_{O}+A_{V}+A_{L}\right)\right]
$$

$A_{O} 、 A_{V}$ and $A_{L}$ are functions of water vapor content and cloud liquid water content :

$$
\begin{aligned}
\mathrm{A}_{\mathrm{O}}=\mathrm{a}_{\mathrm{o} 0}+\mathrm{a}_{\mathrm{o} 1} \mathrm{~V}+\mathrm{a}_{\mathrm{o} 2} \mathrm{~V}^{2}+\mathrm{a}_{\mathrm{o} 3} \mathrm{~V}^{3} \\
\mathrm{~A}_{\mathrm{V}}=\mathrm{a}_{\mathrm{V} 0}+\mathrm{a}_{\mathrm{V} 1} \mathrm{~V}+\mathrm{a}_{\mathrm{V} 2} \mathrm{~V}^{2} \\
\mathrm{~A}_{\mathrm{L}}=\mathrm{a}_{\mathrm{L} 0}\left(1+\mathrm{a}_{\mathrm{L} 1} \mathrm{~V}\right) \mathrm{L}
\end{aligned}
$$

Upward and downward atmospheric radiation could be calculated use the transmission rateof $\mathrm{T}_{\text {eff }}$, atmospheric effective radiation:

$$
\left\{\begin{aligned}
\mathrm{T}_{\text {up }} & =\mathrm{T}_{\text {eff,up }}(1-\tau) \\
\mathrm{T}_{\text {down }} & =\mathrm{T}_{\text {eff,down }}(1-\tau)
\end{aligned}\right.
$$

$\mathrm{T}_{\text {eff }}$ is function of environmental parameters as $\mathrm{T}_{\mathrm{S}}$ and $\mathrm{V}$ :

$$
\begin{array}{r}
\mathrm{T}_{\text {eff,down }}=\mathrm{b}_{\mathrm{D} 0}+\mathrm{b}_{\mathrm{D} 1} \mathrm{~V}+\mathrm{b}_{\mathrm{D} 2} \mathrm{~V}^{2}+\mathrm{b}_{\mathrm{D} 3} \mathrm{~V}^{3}+\mathrm{b}_{\mathrm{D} 4} \mathrm{~T}_{\mathrm{s}} \\
\mathrm{T}_{\text {eff,up }}=\mathrm{T}_{\text {eff,down }}+\mathrm{b}_{\mathrm{U} 0}+\mathrm{b}_{\mathrm{U} 1} \mathrm{~V}
\end{array}
$$

Core content of the sea part is the calculation of the rough sea surface emissivity. When the wind speed reaches $20 \mathrm{~m} / \mathrm{s}$, more than one-third of the sea covered with the whitewater foam ${ }^{[3]}$. The foam surface has a higher microwave emissivity than non-foam surface, which makes it as important as the impact and rough surface effects.Assuming that observed within the field of view of the foam is distributed randomly, its transmit rate is 1 , the foam coverage of $\mathrm{F}$, and then the whole sea the emissivity $\mathrm{e}_{\mathrm{p}}$ can be expressed as:

$$
\left\{\begin{array}{l}
e_{v, h}=(1-F) e_{v, h}^{w}+F+e_{v, h}^{\varphi} \\
e_{3,4}=e_{3,4}^{\varphi}
\end{array}\right.
$$

F use Monahan (1986) bubble mode:

$$
\mathrm{F}=1.95^{-5} \mathrm{w}^{2.56}
$$

$\mathrm{e}_{\mathrm{v}, \mathrm{h}}^{\mathrm{w}}$ is sea surface emissivity unrelated with the wind, contains with two parts, wind speedunrelated content and wind speedrelated content, in another words, calm sea surface emissivitye $\mathrm{e}_{\mathrm{v}, \mathrm{h}}^{0}$ superimposed windspeed $\mathrm{w}$ effects:

$$
\mathrm{e}_{\mathrm{v}, \mathrm{h}}^{\mathrm{w}}=\mathrm{e}_{\mathrm{v}, \mathrm{h}}^{0}+\mathrm{c}_{\mathrm{W} 0}+\mathrm{c}_{\mathrm{W} 1} \mathrm{w}+\mathrm{c}_{\mathrm{W} 0} \mathrm{w}^{2}
$$

The calm seas emissivity $e_{v, h}^{0}$ obtained from the calm sea reflectance $r_{v, h}^{0}$. According to Ellisondielectric constant mode to simulate a range of sea surface temperature-2 $32^{\circ} \mathrm{C}$, the salinity range of $29 \sim 37 \%$, calm sea reflection rate is calculated using Fresnel law:

$\mathrm{r}_{\mathrm{v}, \mathrm{h}}^{0}=\left[\mathrm{c}_{\mathrm{r} 1} \mathrm{t}+\mathrm{c}_{\mathrm{r} 2} \mathrm{t}^{2}+\mathrm{c}_{\mathrm{r} 3} \mathrm{t} \cos \Theta+\mathrm{c}_{\mathrm{r} 4} \cos \Theta+\right.$

$\left.c_{r 5} t \cos 2 \Theta+c_{r 6} \cos 2 \Theta+c_{r 7}\right] / T_{s}(12)$

In which, $\Theta=\left(\mathrm{t}+\mathrm{c}_{\mathrm{r} 8}\right) / \mathrm{c}_{\mathrm{r} 9}, \mathrm{t}=\mathrm{T}_{\mathrm{s}}-273.16(\mathrm{~K})$.

$\mathrm{e}^{\varphi}$ is change of sea emission rate caused by wind direction $\varphi$ :

$$
\left\{\begin{array}{l}
\mathrm{e}_{\mathrm{v}, \mathrm{h}}^{\varphi}=\mathrm{a}_{\mathrm{v}, \mathrm{h}} \cos \varphi+\mathrm{b}_{\mathrm{v}, \mathrm{h}} \cos 2 \varphi \\
\mathrm{e}_{3,4}^{\varphi}=\mathrm{a}_{3,4} \sin \varphi+\mathrm{b}_{3,4} \sin 2 \varphi
\end{array}\right.
$$

Due to the sea surface roughness effect, downward atmospheric radiation generated scattering in all directions within a certain angle range in the sea surface, less than or greater than the angle of incidence of microwave radiation may reach polarization microwave spaceborneradiometer antenna, that impact is corrected use correction factor $\Omega$, which could be calculated by sea surface slope variance $\sigma$ and atmospheric optical thickness $\mathrm{A}^{[4]}$ :

$$
\left\{\begin{array}{l}
\Omega_{\mathrm{v}, \mathrm{h}}=\mathrm{G}(\sigma)+\ln \mathrm{A} \times \mathrm{G}(\sigma)+\ln ^{2} \mathrm{~A} \times \mathrm{G}(\sigma) \\
\Omega_{3,4}=0.5 \times\left(\Omega_{\mathrm{v}}+\Omega_{\mathrm{h}}\right)
\end{array}\right.
$$

In which, $\mathrm{G}(\sigma)=\mathrm{g}_{0}+\mathrm{g}_{1} \sigma+\mathrm{g}_{2} \sigma^{2}, A=-\ln \tau / \sec \theta$, $\sigma^{2}=5.22 \times 10^{-3}\left[1-0.00748(37-v)^{1.3}\right] \mathrm{w}$ $g_{i}(i=0,1,2)$ is empirical coefficient, $v$ is the incident frequency.

\section{PARAMETERSRETRIEVAL PRINCIPLE AND ALGORITHM}

A. sea surface wind vectorretrieval principle and algorithm

Although polarimetric microwave radiometer polarization channel (the $3^{\text {rd }}$ and $4^{\text {th }}$ Stokes parameters) brightness temperatures are two orders smaller than orthogonal channel, they change significantly with wind direction, and size of its amplitude clearly influenced by wind speed, which indicatedtheir capability in wind speed and direction retrievals.

Assuming fixed atmospheric and oceanic background: incident angle is $55^{\circ}$, the sea surface temperature is $290 \mathrm{~K}$, columnar water vapor content over sea is $30 \mathrm{~mm}$,cloudliquid water content over sea is $0.1 \mathrm{~mm}$, seawater salinity $35 \%$. When the wind speed and wind direction change at the same time (wind speed range is $0 \sim 20 \mathrm{~m} / \mathrm{s}$, wind direction range is 0 to $360^{\circ}$ ), Stokes brightness temperatures from each channel variation with the wind vector.The variation characteristics is similar, just the intensity slightly differences. Figure 4 depicts joint sensitivity of sea surface wind speed and direction at four polarimetric channelsat $10.7 \mathrm{GHz}$. 

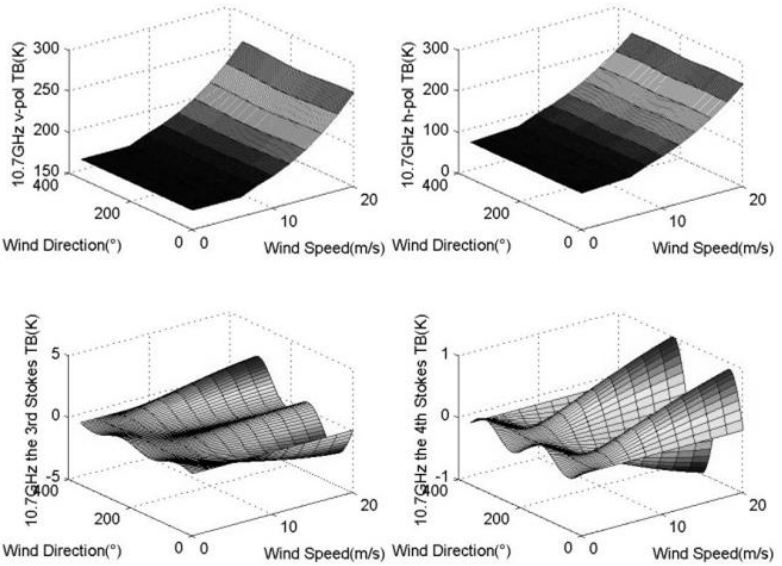

Fig 1.Polarimetric brightness temperature changes with sea surface wind

vector at $10.7 \mathrm{GHz}$

It is clearly seen from the Fig.1, that the horizontal and vertical polarization channel show good correlation with sea surface wind speed, third and fourth Stokes parameters show good correlation with wind direction. Ratio of the $3^{\text {rd }}$ and $4^{\text {th }}$ Stokes parameter can be initially identified the quadrant angle of the wind direction, which could be useful in wind direction ambiguity and initial value estimate inretrievals.

So far, the use of polarimetric microwave radiometer observations brightness temperature of the sea surface wind vectorretrieval algorithm can be divided into three categories: statistical methods, semi-statistical methods and physical algorithm. Statistical algorithms derive empirical relationshipsfrom brightness temperature measurement and feature parameters, such as multiple regression algorithm or modified D-matrix algorithm.Statistical algorithms can supplysea surface wind speed, sea surface temperature, atmospheric water vapor, sea surface wind, etc., which provide the necessary environment field in wind direction retrieval. Semi-statistical algorithm, also known as physical statistical method, different statistical algorithms that regression calculated using the radiative transfer model to simulate the brightness temperature, for example, theMLE (Maximum Likelihood Estimate) method, normally used for wind direction inversion ${ }^{[5]}$.Semi-statistical algorithm could do a joint inversion of the sea surface wind direction and speed, but wind direction and speed accuracy mutual restraint in the same time. Physical inversion algorithm proposed by Wentz ${ }^{[6]}$, the nature of the problem is nonlinear equations, accurate and efficient inversion depends on the accuracy of feature model and the validity of the equations solution.

\section{B. Other physical parameters inversion}

Microwave brightness temperature is a direct reflection of the speed of the wind pressure or friction. The friction speed not only depends on the wind speed, but also has relationship with the mechanical mixing sea stream velocity. At the same time, due to the impact of air-sea interaction,microwave brightness temperature changes with the sea surface radiation, sea surface temperature, wind speed, water vapor content,cloud liquid water content and their physical interaction. Therefore, in addition to sea surface wind vectors, it is capable of remote sensing sea surface temperature, atmospheric water vapor content, the total content of cloud liquid water, precipitation and other ocean and atmospheric physical parameters using polarimetric microwave radiometer.

Water vapor content retrieval with single-channel microwave radiometergenerally optsfrom atmospheric absorption microwave band,whichis mainly dependent on the water vapor but relatively transparent.Channel center frequency should deviate from the absorption line center $(22.235 \mathrm{GHz})$, so atmospheric radiance temperature maindecided by the total water vapor content, which has little to do with the water vapor vertical distribution. In addition, in certain conditions, the satellite radiometer measured value and the total water vapor content or the total content of liquid water into the linear relationship. Solution the total content of the water vapor and liquid water content at the same time, usually select two channels respectively near $22.235 \mathrm{GHz}$ (water vapor absorption lines) and $31.4 \mathrm{GHz}$ (water vapor window), constitute a dual-channel microwave radiometer, establish equations and combined solution.

In rainy conditions, microwave radiative transfer equation forspaceborne microwave radiometer brightness temperature is the same form with no rain, in the form of:

$$
T_{B}(\theta)=T_{B b} \tau(0, \infty)+\int_{0}^{\infty} T(z) W(z) d z
$$

However, the transmittance function and the weighting function of specific expression, atmospheric attenuation coefficient should be considered to the attenuation coefficient of the precipitation particles. Microwave radiometer remote sensing of precipitation, according to the characteristics of its observation, could use absorption method or scattering method. Absorption method use longer wavelengths, the scattering in the radiation transmission path can be ignored. Scattering method select the higher frequency, the scattering source is ice at cloud topfrom rainfall zone. Reduce of radiation brightness temperature indicated increase in the number of ice crystals above frozen layer, which shows precipitation intensity increases and contrary with absorption method.

\section{SUMMARY}

Polarimetric microwave radiometer has been widely used in parameter retrievals such as sea surface wind vector, sea surface temperature, water vapor content,cloud liquid water content, etc.;especially the polarimetric information is useful to remove the wind direction ambiguity.Therefore, polarimetric microwave radiometer represented by WindSat opened up new areas of passive microwave remote sensing, which has important theoretical and research value. 


\section{REFERENCES}

[1] Gaiser P W, Twarog E M,et al. "The WindSat space borne polarimetric microwave radiometer: sensor description and mission overview." in Geoscience and Remote Sensing Symposium, 2004.

[2] Bettenhausen M H, Smith C K, et al. "A Forward Model for the WindSat Physically-based Retrieval Algorithm." IEEE Transactions on Geoscience and Remote Sensing 44 (2006): 597.

[3] Steven S P, Rose L A, et al."Recent Measurements of the Microwave Emissivity of Foam: Effects on WindSat
Brightness Temperatures," in WindSat $\mathrm{Cal} / \mathrm{Val}$ and Science Meeting, Solomons, MD, 2004.

[4] Liujingyi, Wangzhenzhan, et al. "A Wind Vector Retrieval Method for Polarimetric Microwave Radiometer WindSat."Remote Sensing Technology and Application 22 (2007): 210 (in chinese)

[5] Meissner T, Wentz F J. "Ocean retrievals for WindSat: radiative transfer model, algorithm, validation." inGeoscience and Remote Sensing Symposium, 2005.

[6] Wentz FJ. "Measurement of Oceanic Wind Vector using Satellite Microwave Radiometers." IEEE Trans. Geosci. and Remote Sensing, 30 (1992): 960-972. 